\title{
LA ARQUITECTURA INSTITUCIONAL DE LA UNIÓN EUROPEA: DE LAEKEN AL PROYECTO DE TRATADO CONSTITUCIONAL
}

\author{
Antonio MORENO JUSTE \\ Universidad Complutense de Madrid
}

\section{EL COMPLEJO PROCESO DE REFORMA DE LA UNIÓN EUROPEA}

Desde principios de la pasada década se ha podido observar como periódicamente se han ido produciendo renegociaciones del Tratado de la Unión cuyos resultados han conducido a una misma conclusión: cada vez es más difícil comprender las sucesivas modificaciones y parcheos introducidas en las reglas del juego comunitarias, sobre todo, si se tiene en cuenta que el proceso de integración se encuentra a las puertas de la mayor ampliación experimentada en sus más de cincuenta años de historia (AREILZA CARVAJAL, 2003, 43).

Una sensación que progresivamente ha conducido al convencimiento mayoritario de que las reformas selectivas y parciales no son suficientes ni garantizan la eficacia de la Unión y cuyo corolario, entre los círculos europeístas, ha sido la demanda de un modelo institucional claro y definido que transforme la Unión Europea en una estructura coherente, racional y transparente y que a su vez permita el paso desde una comunidad de democracias a una democracia directa (HABERMAS, 2001, 124). Ese convencimiento coadyuvó la puesta en marcha de un nuevo proceso de reforma que ha conducido a que la Unión Europea disponga actualmente de un anteproyecto de Constitución que puede alterar sustancialmente los principios y los equilibrios de poder de la Europa de los veintiocho.

En nuestra opinión, son varios los factores que pueden ayudarnos a explicar como se ha llegado a esta situación, casi impensable a finales de 2002. Unas claves que pueden considerarse bien, como consecuencia del aumento de las dudas sobre si las instituciones de la Unión y los mismos Estados miembros serían capaces por sí mismos de responder a los retos planteados por la posguerra fría (ATTINA, 2001, 172 y ss.), o bien, como representación de las incertidumbres que en el ámbito de la integración europea ha generado el triple impacto de la globalización económica, la crisis del Estado-nación y los cambios introducidos por la sociedad de la información (HELD, 1997, 96). Entre ellas -y sin ningún afán de exhaustividad-, cabe destacar: 
- Los múltiples flecos pendientes del Tratado de Unión Europea acordado en Maastricht y su impacto sobre la agenda comunitaria a lo largo de los noventa. Al respecto, no puede olvidarse que el Tratado de Maastricht debe entenderse, ante todo, como la respuesta comunitaria a un doble desafío interno y externo -en el plano exterior Maastricht fue la reacción a los cambios vertiginosos sucedidos en Europa desde 1989 y las transformaciones operadas en el escenario internacional; en el interno, el TUE fue resultado de las implicaciones político-institucionales, sociales, económicas y monetarias de la creación del Mercado Unico y de la Unión Económica y Monetaria (ORTEGA, A. 1997, 20)

- El previsible impacto de la ampliación hacia el Este. El Consejo Europeo de Copenhague de diciembre de 2002 ha sido considerado como el plato fuerte de un proceso que se inicio en 1989 y que se caracterizó por el intento de integrar la Europa más amplia y de sobreponerse a la división del continente creada por la guerra fría. Una ampliación para configurar una Europa ${ }^{1}$, y que ha condicionado y presionado sobre la ineludible reforma institucional de la Unión Europea y que al mismo tiempo ha planteado una serie de dudas sobre su futuro: ¿Es razonable arriesgar la frágil estructura de la Unión, incorporando nuevos países que arrastran graves dificultades políticas y económicas? ¿Podrán las instituciones europeas soportar un mayor peso burocrático, resultado de las nuevas incorporaciones ya previstas? (TOULEMON, 2000, 297).

- La persistente crisis institucional consecuencia del agotamiento del método intergubernamental basado en conferencias intergubernamentales como fórmula de avanzar en el proceso de construcción europea al definir las negociaciones en términos de poder. Los parcos resultados alcanzados tanto en Niza (2000) como en Amsterdam (1997) han sido considerados consecuencia directa de la primacía de la aritmética de los Estados sobre la ambición europeísta. al tiempo que pusieron en evidencia la falta de proyecto común capaz de ilusionar a la ciudadanía europea dotar de contenido a la identidad europea $^{2}$. En este sentido, han sido talleres para apuntalar la arquitectura de

\footnotetext{
${ }^{1}$ Este es el término expresado en las conclusiones del Consejo Europeo de Copenhague para representar el proceso constituyente dentro del marco de una Unión Europea: "Una Europa en el proceso constituyente".

${ }^{2}$ En ese sentido, parece clara la ausencia de canales adecuados para superar esta situación. En la actualidad, los medios de comunicación transnacionales sólo pueden establecer un contexto comunicativo políglota y ello sólo será posible a medio plazo si los sistemas de educación nacional dan prioridad al aprendizaje de otras lenguas. Es más, si prosperan las iniciativas en este sentido, los legados culturales de una historia común europea se podrán ir difundiendo hacia el exterior desde unos centros nacionales dispersos lo que determinará que los ciudadanos se sentirán
} 
la Unión Europea más que cunas de una nueva visión de Europa. Una situación agravada por el hecho de que Europa no ha encontrado el tiempo suficiente para asimilar sus propias transformaciones porque pasó a toda prisa de una reforma a otra y todo ello comoconsecuencia de que la Unión Europea parece obsesionada con sus ambiciones lo que le determina a estar "condenada al éxito" (WeSSELS Y DiETRICHS, 2003, 11).

- El retorno de una visión más nacional de Europa, menos comunitaria y más netamente intergubernamental. Una visión surgida en el contexto de la crisis económica de los primeros noventa y más propia quizá de la posguerra fría y en la que la diversidad y la realidad nacional volvieron a ser valores en alza entre la misma ciudadanía europea. De hecho, en la última década se ha observado como el intergubernamentalismo o neoestatalismo han tratado cada vez con mayor ahínco de desplazar a los tradicionales procedimientos comunitarios ${ }^{3}$. Sobre ese contexto ha venido a incidir el 11 de septiembre con su notable impacto sobre las mentalidades, incrementando la demanda general de seguridad, sobre todo en Estados Unidos, y que, por efecto contagio, se ha trasvasado a Europa reverdeciendo algunas de las funciones tradicionales del Estado-nación, suministrar seguridad, al tiempo que ha favorecido la dinámica de las alianzas intergubernamentales (VIDAL-FOLCH, 2003, 25).

- Y, por último, los problemas de legitimación democrática en el seno de la Unión. A los tradicionales déficits democráticos existentes en el proceso de construcción europea, durante los últimos años, se ha unido el problema de que la legitimidad democrática se va viendo socavada además -de forma no tan evidente pero sí más duradera y profunda-, por la creciente necesidad de coordinación, motivada por el aumento de la interdependencia y que se intenta subsanar mediante acuerdos interestatales, ámbito que resulta mucho más opaco a la ciudadanía ${ }^{4}$. De hecho, la Unión Europea y su proceso de

gradualmente unidos en una política cultural común. No olvidemos que la sociedad contemporánea se ve sujeta a un continuo proceso de construcción-deconstrucción-reconstrucción no sólo de las identidades individuales, sino también de las colectivas (BERSTEIN, S. 2000, 98 y ss).

${ }^{3}$ Los intentos que se han llevado a cabo para modificar el sistema de gobierno comunitario a partir del dualismo entre la intergubernamentalidad del Consejo de Ministros, el Consejo Europeo y el Consejo de Representantes permanentes de la Unión(COREPER) y el método comunitario articulado por el Parlamento Europeo, la Comisión Europea y el Tribunal de Justicia y el resto de las instituciones y órganos de la UE, no han dado soluciones de futuro, abocando a la Unión a una dinámica de reforma permanente (LouIS, 2002, 226)

${ }^{4}$ Sobre este particular, reiteradamente puesto de manifiesto por Schmitter o Weiler, merece la pena destacar la invocación al poder de veto que tienen todos los participantes en las negociaciones intergubernamentales por parte de Scharpf. Este autor sostiene que los resultados de tales negociaciones basan su legitimidad en la regla según la cual todos los participantes deben dar su consentimiento a las decisiones y que ninguno lo hará si, pensándolo bien, saliera peor parado 
toma de decisiones -burocrático en su mayor parte-, lo que ofrece es un ejemplo del tipo de déficit democrático provocado por el salto de las instancias decisorias nacionales a las comisiones interestatales de representantes gubernamentales. (SIEDENTOP, 2000, 157)

La principal consecuencia que se deriva de la interacción entre estos procesos fue la exigencia de una redefinición en profundidad de muchos de los principios de política europea que alejasen los riesgos de inmovilismo y de disolución de la Unión tras la consecución de la unión económica y monetaria. Un debate que se abrió con el horizonte de una mejora de la interacción entre el sistema institucional comunitario y el de los Estados miembros para progresivamente ir adquiriendo un carácter constituyente o constitutivo -según la posición del observador-, con la Convención Europea.

Ciertamente, la insuficiencia inherente de las revisiones del Tratado alentó el proceso de debates y negociaciones habituales y prácticamente constantes sobre la reforma de la Unión Europea que abocaron a la Convención sobre el futuro de Europa. Pero su convocatoria fue algo más que la constatación de que una Unión ampliada no podía seguir funcionando como había funcionado la Europa de los Quince ya que puso de manifiesto la necesidad de una Constitución entendida como un pacto republicano en torno a la soberanía europea- en la que, de una parte, se delimitasen derechos y deberes de los ciudadanos de Europa y, de otra, se estableciese claramente donde reside el poder y las formas de controlarlo (LEINEN, 2001, 6-9).

A partir de esta fórmula se logró trascender la mera exigencia de simplificar la maraña de textos legales existentes, para dar cauce a la vieja aspiración de clarificar qué es Europa como paso previo a la discusión de como debe ser gobernada. Sin embargo, el Proyecto de Tratado estableciendo una Constitución para Europa expresa perfectamente las contradicciones, incertidumbres y rupturas que jalonan el proceso de construcción europea en la última década.

De una parte, el proyecto de Constitución es un texto completo (consta de un preámbulo y 460 artículos divididos en tres partes, más una cuarta de disposi-

\footnotetext{
que si bloqueara la negociación haciendo fracasar todo el proceso. No obstante, este argumento no tiene en cuenta el carácter tan derivado como disminuido de tal legitimación, es decir, no tiene en cuenta que los acuerdos suparanacionales no están sujetos a las presiones de legitimación en la misma medida que las decisiones tomadas en el ámbito nacional, ni el hecho de que el proceso institucionalizado de formación de la voluntad en el Esado-nación está sujeto a normas y valores reconocidos intersubjetivamente y no se reduce a un compromiso o, con otras palabras, a una componenda de las partes interesadas. Asimismo, y obviamente, las políticas deliberativas de los ciudadanos y sus representantes no pueden reducirse a la pericia de los especialistas, por ejemplo decisiones del Banco Central Europeo. Vid. (HABERMAS, J. 2000, 122-123).
} 
ciones finales así como cinco protocolos) que da el paso más importante hacia la unión política europea desde la firma de los Tratados Fundacionales de las Comunidades Europeas en 1957, al tiempo que da respuesta a los tres objetivos fundamentales que la Declaración de Laeken le fijó a la Convención Europea: acercar Europa a los ciudadanos, preparar la UE para la ampliación y proveerla de los instrumentos necesarios para que pueda convertirse en factor de estabilidad y "líder para numerosos países y pueblos" en el nuevo entorno de la globalización. No obstante, parece olvidar que el desafío real es conseguir un documento comprensible y que signifique algo para los ciudadanos europeos ya que será a ellos a quien se deba "vender la nueva Europa" y probablemente esa labor será más ardua de lo que en los círculos europeos de la Convención se ha pensado (WESSELS Y DIETRICH, 2003, p.17).

De otra, tras la presentación del Proyecto de Tratado Constitucional en el Consejo Europeo de Salónica de Junio de 2003 y coincidiendo con el inicio de la Conferencia Intergubernamental el pasado 4 de octubre en Roma, se ha evidenciado el tradicional del escollo del reparto de poder entre los Estados miembros. El texto final de la Convención se logró a través del complejo e inestable equilibrio alcanzado entre federalistas y antifederalistas, entre miembros fundadores y aspirantes a la adhesión, países grandes y países pequeños, en la recta final de la Convención. Pero fue un compromiso al que se llegó por consenso y no por unanimidad cuando la última palabra la tienen todavía los Estados miembros. Un problema cuya la resolución esta en función de cómo se responda a la cuestión de si el status quo institucional, en el que los Estados equilibran unos intereses nacionales opuestos mediante negociaciones intergubernamentales debe ser defendido incluso al precio de una carrera a la baja o, si la Unión Europea debiera desarrollarse más allá de su forma actual de alianza de Estados avanzando de forma progresiva hacia una federación de Estados y ciudadanos. Y ese es el fondo de la cuestión que aún sigue sin dirimirse ya que el texto surgido de la Convención se encuentra sometido a un doble enfrentamiento: de un lado, entre los partidarios de reforzar las instituciones comunes y los que desean que los Gobiernos, los Estados, sean los que hagan y deshagan; de otro, quienes consideran que en democracia el peso de cada cual se mide de acuerdo con su población frente a quienes entienden que cada socio del club, cada Estado, debe tener una fuerza sólo matizada por el número de habitantes.

Ese panorama, por último, quedaría incompleto sino se hiciese referencia a la cuestión planteada por el papel que debe desempeñar Europa como actor global en las relaciones internacionales y al problema de la falta de cohesión entre los Estados miembros de la Unión sobre algunos temas clave de política exterior y de seguridad como se ha evidenciado ante la guerra de Irak que ha provocado una de las mayores crisis internas del proceso de integración. Las divisiones y fracturas 
que se han observado entre los gobiernos europeos han determinado que la respuesta a la hegemonía unilateral americana sólo pueda calificarse de completo desastre al poner de manifiesto la falta de voluntad política pero también de posibilidades reales para el desarrollo de una identidad europea de seguridad y defensa. Lo cierto es que, hoy por hoy, la Unión Europea no responde a las exigencias de los Estados Unidos pero tampoco a la de los ciudadanos europeos: las expectativas abiertas han sido muy superiores a los resultados obtenidos ${ }^{5}$.

\section{LA CONVENCIÓN EUROPEA Y EL DEBATE SOBRE EL FUTURO DE EUROPA}

\section{El punto de partida}

A grandes rasgos, el proceso que conduce al Proyecto de Tratado para una Constitución Europea se pone en marcha con el reconocimiento de los Estados signatarios del Tratado de Niza de su propio fracaso al programar en la Declaración 23 otra reforma para 2004, una circunstancia que contrasta con el éxito de la Convención que preparó la redacción de la Carta de Derechos Fundamentales de la Unión Europea y cuyos resultados fueron presentados en la misma cumbre de Niza. De ese ambiente será de donde surja la propuesta de sustituir el tradicional sistema intergubernamental para la revisión de los Tratados de la Unión por un debate de carácter global y abierto que se articule en varias etapas (CONSTANTINESCU, 2002, 19).

A grandes rasgos, pueden señalarse tres fases. La primera, un debate abierto a toda la ciudadanía y todos los sectores económicos, sociales, universitarios donde se discutiese sobre el futuro y la finalidad de Europa, se inició oficialmente el 7 de marzo de 2001 con la Declaración Interinstitucional inaugurando el debate sobre la evolución futura de la Unión Europea, adoptada conjuntamente por las presidencia sueca y belga del Consejo, el Parlamento Europeo y la Comisión. Unos meses después, el 25 de julio, Romano Prodi, presidente de esta última, hizo pública su contribución al debate con la presentación del Libro Blanco sobre la gobernanza de Europa. Al mismo tiempo y de forma paralela, todos los Estados miembros y parte de los países candidatos llevaron a cabo también diversas iniciativas con el objeto de fomentar el debate entre partidos políticos, círculos académicos, sociedad civil, grupos económicos y sociales, ya

\footnotetext{
${ }^{5}$ Acerca del debate abierto en torno al papel internacional de Europa interesa ver. KAGAN, R. Poder y debilidad. Europa y estados Unidos en el nuevo orden mundial, Madrid, Taurus, 2003. En dirección distinta véanse los interesantes análisis de: Joseph NYE, La paradoja del poder norteamericano, Madrid, Taurus, 2003 y Emmanuel ToDD, Después del imperio, Madrid, Foca, 2003.
} 
que la Declaración 23 expresamente hacia énfasis en la necesidad de promover los debates a escala nacional.

Esta etapa concluyó el 15 de diciembre de 2001 con la adopción por el Consejo Europeo de Laeken de una Declaración que encomendaba la preparación de la reforma a una Convención sobre el futuro de Europa con tres objetivos: una mejor división y definición de la competencias de las instituciones de la UE; una simplificación de los instrumentos de la Unión; más democracia, transparencia y eficacia en la UE, y la formulación de alternativas de cara a la creación de una Constitución para los ciudadanos europeos. Esta fase de debate estructurado se desarrolló entre marzo de 2002 y junio de 2003 y en ella se ha efectuado la redacción del proyecto de Constitución.

Por último, la tercera etapa de debate adopta forma tradicional de Conferencia Intergubernamental. En esencia, es la instancia encargada de dar forma definitiva a la reforma y, consecuentemente, tiene capacidad para modificar e incluso rechazar el borrador constitucional preparado por la Convención. Su apertura se produjo el 4 de octubre del 2003 y su cierre se ha previsto para el Consejo Europeo de Roma de diciembre de 2003. No obstante, la presidencia italiana ha manifestado dudas al respecto, en referencia a las reservas planteadas por España y Polonia sobre el sistema de votos en el Consejo; de los países pequeños y los de la ampliación respecto al número de comisarios de la Comisión y, por parte de Gran Bretaña y Dinamarca sobre la Política Exterior y de Seguridad Común.

\section{El método de la Convención Europea}

La convocatoria de la Convención no aclaraba cuál iba a ser su papel ya que la única evidencia en aquel momento residía en la insuficiencia del método anterior. Se desconocía, incluso, si su labor iba a consistir en poco más que un trabajo preparatorio para la ulterior decisión a tomar respecto a la reforma institucional por la Conferencia Intergubernamental, o si implicaba la adopción de una dimensión constitucional o constituyente. Y en ese sentido, se dudaba sobre si el producto iba a ser una propuesta de Tratado, si un Tratado o varios, si un Tratado Constitucional o una Constitución. ${ }^{6}$

\footnotetext{
${ }^{6}$ Según José María Beneyto, el término constitución evoca un texto jurídico dotado de un aura especial. La Constitución es el texto jurídico fundamental de la organización del Estado y una decisión esencial sobre la forma de convivencia de determinada comunidad. Y desde esta perspectiva que podemos definir como liberal se viene interpretando por parte de muchos el significado del término constitución en su acepción comunitaria. Sin embargo, otros muchos consideran que en el ámbito de la construcción europea debe efectuarse una lectura del término constitución más en consonancia con el significado profundo del proceso de integración en lo relativo a las re-
} 
Lo cierto es que la Declaración de Laeken, al pronunciarse a favor de la Convención, de alguna forma, sugería un respaldo formal al método federal, y esa es la principal novedad de la reforma iniciada en Laeken, en que por primera vez a lo largo de la historia de la construcción europea, se encarga la preparación de una Conferencia Intergubernamental a un órgano democrático que pone al mismo tiempo en pie de igualdad la doble legitimidad de la Unión, la nacional y la europea ${ }^{7}$. Desde esa perspectiva, puede afirmarse que la Convención la Convención europea supone un salto cualitativo en el método de reforma de los Tratados (ALDECOA, 2003 (a), 30) ya que, de una parte, se asemeja al método federalista propuesto en el Congreso de la Haya de 1948 (por oposición el método funcionalista o método Monnet que ha impulsado desde el plan Schuman el proceso de integración) y de otra, cuando menos, implica una superación parcial del método diplomático aplicado en las sucesivas conferencias intergubernamentales convocadas desde el Acta Única Europea.

Esa naturaleza híbrida, federal e intergubernamental, de la Convención se manifiesta perfectamente en su composición ya que contó tanto con representantes de los 15 Estados miembros (15 de los gobiernos, 30 de los Parlamentos nacionales) como de las instituciones comunes (16 eurodiputados y 2 comisarios). Junto a ellos el Consejo Europeo de Laeken nombró un Presidente (Velery Giscard D'Estaing) y dos vicepresidentes (el italiano Amato y el belga Dehaene $)^{8}$. Asímismo, estuvieron presentes como observadores el Defensor del

laciones entre las instituciones europeas y los Estados miembros. En este sentido, el significado actual del término constitución cuando se aplica al contexto europeo "hace referencia a la simplificación de los Tratados y al reconocimiento del actual sistema comunitario que presenta los rasgos y caracteres de una constitución, según ha señalado en diversas ocasiones el Tribunal de Justicia de Luxemburgo". Se trataría, en definitiva, de la "europeización" de los derechos constitucionales, de las Constituciones y de los Tribunales constitucionales de los Estados miembros. Es decir, el problema de las relaciones entre el sistema comunitario europeo y los sistemas constitucionales de los Estados miembros en la perspectiva de un ordenamiento común. Desde este punto de vista, parece evidente que existe una Constitución europea comprendida como un sistema abierto, formado por dos niveles complementarios: el que procede del ordenamiento constitucional de los Estados miembros y el propio ordenamiento comunitario, entre los que existe una interrelación y una interconexión constantes. "Es más, si se admite esta premisa de la existencia de una Constitución propia, en el sentido formal, de la UE, parece evidente que el actual debate europeo tiene como horizonte la mejora de la interacción entre el sistema institucional comunitario y el de los EE.MM y cómo ello puede redundar en beneficio del conjunto no sólo de los Estados, sino también de los ciudadanos". (BENEYTO, J.Ma , 2001, 132 y ss).

${ }^{7}$ A favor de esta dinámica se habían pronunciado a lo largo de 2001 tanto el Parlamento Europeo como diferentes círculos europeístas.

${ }^{8}$ De la organización y coordinación de los trabajos se encargó un Presidium que estuvo integrado por el Presidente, los dos Vicepresidentes y nueve miembros (los representantes de todos los gobiernos que durante la Convención ostenten la Presidencia de la Unión, dos representantes 
Pueblo europeo, seis representantes del Consejo Económico y Social, dos de ellos en nombre de las regiones con competencias legislativas propias.

Por otra parte, es necesario destacar que la Convención trabajo desde una lógica postampliación, dado que los trece Estados candidatos fueron invitados a tomar parte de los trabajos con igual representación que los Estados miembros. Y de esa composición surge una cierta indefinición en torno a su naturaleza, ya que la Convención ha sido a un tiempo una asamblea constituyente, un comité de expertos y una conferencia diplomática encubierta con todos los aspectos positivos y negativos que dimanan de esa ambigua situación.

En primer lugar, los debates de la Convención han sido más plurales y transparentes que los de las conferencias diplomáticas que hasta ahora habían reformado los Tratados, sin embargo, la falta de participación ciudadana, a pesar de los intentos iniciales de organizar foros ciudadanos y de haber superado el secretismo de las conferencias intergubernamentales, al abrir las puertas de la negociación día a día a través de internet, ha sido uno de sus principales déficits.

En segundo lugar, la Convención ha superado los mandatos de los Consejos Europeos de Niza y Laeken, pretendiendo incluso emular el espíritu de la Convención de Filadelfia en 1787 que redactó la Constitución de Estados Unidos, pero, a pesar de ello, sus resultados han sido limitados al menos por cuatro factores (AREILZA CARVAJAL, 2003, 44)

- Los trabajos se han producido en un contexto de gran desconfianza ciudadana hacia el proceso de construcción europea y hacia las instituciones de la Unión, bien a causa de lo que muchos consideran que son demasiadas competencias o bien porque considera que hace demasiado poco, según quien realice la crítica.

- Como era previsible ha sufrido el impacto directo de la crisis de la conciencia europea, dividida e inquieta.

- Ha trabajado contrareloj, sin poder alargar el calendario para poder abordar el ambicioso conjunto de cuestiones a abordar.

- Se ha debatido entre elaborar una Constitución en el vacío y tener en cuenta la gran constitucionalización de los actuales tratados en el método comunitario.

de los Parlamentos nacionales, dos representantes de los diputados del parlamento Europeo y dos representantes de la Comisión. 
A estas limitaciones se debe añadir el enfrentamiento entre los propios europeos respecto a la actitud de Estados Unidos ante el régimen de Sadam Hussein y posteriormente con la guerra de Irak que vino a coincidir con la recta final de los debates de la Convención, provocando la mayor fractura sobre el papel exterior de la Unión Europea desde el conflicto de Bosnia (ORTEGA, M., 2003, 65). Y todo ello en un contexto de adversa coyuntura económica, de un ciclo histórico enfrentado con la lógica comunitaria, a lo que habría que añadir la poliédrica y controvertida personalidad de su presidente, Giscard D'Estaing, que ha despertado todo tipo de suspicacias y recelos.

En tercer lugar, no pueden ignorarse las notables divergencias existentes sobre el futuro de Europa en el seno de la Convención. En un extremo, están los más entusiastas (abogados del sueño de Victor Hugo) sobre unos Estados Unidos de Europa, partidarios de un Estado federal capaz de convertirse dados sus recursos y población en una superpotencia. En el extremo opuesto se encuentran los partidarios de que Europa sea poco más que un Mercado Común como pretenden los euroexcepticos (la palabra federal, por ejemplo, salió del texto por imposición británica). Entre ambas, caben todo tipo de propuestas y posiciones de defensa cerrada de intereses nacionales ${ }^{9}$, aunque lo cierto es que ni los antifederalistas presentes en la Convención han presentado propuestas para ir hacia atrás, ni tampoco nadie ha pedido crear un super-Estado Federal europeo.

Asímismo, se ha podido observar una reacción defensiva de las opiniones públicas y de buena parte de la clase política europea ante el síndrome de decadencia y crisis del Estado-nación (declive de los recursos del Estado para efectuar tareas de control, aumento de los déficit de legitimidad de los procesos de toma de decisiones; creciente incapacidad de desempeñar el genero de funciones directivas y organizativas que contribuyen a asegurar su legitimidad...) que en el ámbito comunitario se pueden traducir como las transferencias de soberanía en materias sensibles y en la Convención aparecieron en forma del reparto de poder en las instituciones o el diseño de una política exterior común. Problemas que hoy amenazan con difuminar los logros de la Convención cuando no recaer en una franca involución.

En definitiva, la Convención se ha debatido internamente entre un decantamiento excesivo hacia los alegatos del federalismo unionista que insiste en avanzar hacia una utopía todavía lejana y un pragmatismo alicorto que hubiera

\footnotetext{
${ }^{9}$ Propuestas de un rígido catálogo de competencias; idea de los países grandes de establecer un directorio que ordenase y articulase un club de veinticinco socios, pretensión de convertir a la Comisión, institución motor de los avances de la construcción europea, en una especie de secretaría técnica del Consejo, etc.
} 
convertido el texto en irrelevante o una defensa de los propios intereses que imposibilitase acuerdos y soluciones consensuadas lo que hubiese implicado que todo quedaba por decidir en la ulterior Conferencia Intergubernamental que corona el proceso con las previsibles consecuencias observadas desde Maastricht (VIDAL FOLCH, 2003, 24). Es decir, la incapacidad de alumbrar una reforma institucional válida para una Europa de veinticinco Estados, de 450 millones de ciudadanos y dotada de la suficiente agilidad, de una estructura más democrática, más transparente y más eficiente.

\section{La Agenda de la Convención y el desarrollo de los trabajos}

La Convención sobre el futuro de Europa comenzó sus trabajos el 27 de febrero de 2002 y aunque la Declaración de Laeken fijaba el plazo de un año para los mismos, (que se cumplió en marzo de 2003) este resultó alargado por los Consejos Europeos de Copenhague, primero, y Salónica, después, hasta julio de este mismo año, en que se ha disuelto tras casi diecisiete meses de actividad ${ }^{10}$. Respecto a la organización de sus trabajos, estos se pueden dividir en tres fases: escucha, estudio y, deliberación y redacción, cada una de ellas de una duración de entre cinco y seis meses (ALDECOA, 2003 (b), 5-7).

- La primera de ellas de escucha o audiencias, se ha desarrollado entre marzo y junio de 2002, con el objetivo de establecer las cuestiones que la Convención debía examinar, a través de los debates en sesión plenaria entre los miembros de la Convención y de la audiencia a la sociedad civil y a la Convención de los jóvenes ${ }^{11}$.

- La segunda etapa fue la de estudio y deliberación, caracterizada por la constitución de once Grupos de Trabajo y el debate de sus conclusiones. De los resultados de las sesiones plenarias de la primera fase se establecieron ya los primeros consensos y una primera aproximación a las cuestiones necesitadas de estudio técnico detenido para lo cual se crearon once Grupos de Trabajo

\footnotetext{
${ }^{10}$ La Convención ha celebrado aproximadamente una sesión plenaria mensual, compuesta por dos medias jornadas, si bien al final del periodo se llegaron a dos sesiones por mes para acelerar los trabajos. Sus cifras son: 28 sesiones plenarias que equivalen a 56 días abiertas al público y a los medios de comunicación; 1812 intervenciones de los miembros de la Convención y 995 enmiendas presentadas.

${ }^{11}$ En esta fase se celebraron seis sesiones plenarias sobre las expectativas que los convencionales tienen de la Unión Europea (21-22 de marzo); las misiones de la Unión Europea (15-16 de abril); la Unión Europea llevando a cabo sus funciones: eficiencia y legitimidad (23-24 de mayo); un área de libertad, seguridad y justicia y el papel de los parlamentos nacionales (6-7 de junio); audiencia a la sociedad civil (24-25 de junio) y acción exterior, defensa y audiencia a la Convención de los jóvenes (11-12 de julio).
} 
entre mayo y septiembre ${ }^{12}$ a los que se sumo en noviembre, debido a la petición de un buen número de convencionales, un nuevo Grupo relativo al estudio de la Europa Social. En esta etapa, la Comisión Europea entró directamente en el debate constitucional con la publicación del documento de trabajo Una Constitución para Europa, el 4 de diciembre de 2002. ${ }^{13}$.

- La tercera etapa, de redacción, se inició en enero de 2003, transcurriendo hasta la aprobación del texto por consenso el 13 de junio de 2003, viéndose prorrogada hasta el 10 de julio, en que se remataban los trabajos. En esta fase, el Presidium decidió la constitución de varios Círculos de Debate, que estudiaron aspectos relacionados con la reforma del Tribunal de Justicia, el procedimiento presupuestario y los recursos propios de la Unión Europea. Por otra parte, el Presidium solicitó a los Servicios Jurídicos del Consejo, el Parlamento y la Comisión que nombraran a expertos a los que encargar un informe técnico sobre el traslado de las disposiciones jurídicas de los Tratados de la Comunidad Europea y Tratado de la Unión a la parte segunda del Proyecto constitucional.

Este grupo de expertos entregó su informe el 17 de marzo, en el que se recoge el ejercicio técnico de modificación de los artículos, su adaptación lingüística y la eliminación de disposiciones, resultantes de la fusión de los distintos Tratados en uno solo. En esta fase, a partir de febrero, el Presidium fue presentando las propuestas de redacción de los distintos artículos, a las cuales los convencionales iban adjuntando sus enmiendas que luego eran debatidas a lo largo de posteriores sesiones plenarias, tratando de aproximar posturas hasta llegar a la redacción definitiva. Las dos cuestiones que más dificultades entrañaron, y cu-

\footnotetext{
${ }^{12}$ Los seis primeros, llamados de primera hornada, el 17 de mayo: principio de subsidiariedad, Carta de Derechos Fundamentales, personalidad jurídica de la Unión, papel de los parlamentos nacionales, competencias complementarias y gobernanza económica. Posteriormente, el 12 y 13 de septiembre se aprobó la constitución de cuatro grupos más, la segunda hornada, encargados del estudio de la acción exterior, la defensa, la simplificación de los procedimientos e instrumentos legislativos y el establecimiento de un área de Libertad, Seguridad y Justicia.

${ }^{13}$ Este proyecto denominado "Penélope" generó una amplia polémica por estar inspirado en el federalismo de izquierdas y chocar tanto con las tendencias federalistas moderadas como con los partidarios del intergubernamentalismo en mayor o menor nivel. El proyecto de la Comisión pretendía responder a tres cuestiones presentadas con anterioridad en su comunicación Un proyecto para la Unión Europea:"Las expectativas -afirmaba el documento de la Comisión- de los ciudadanos invitan a concentrarse en tres cuestiones fundamentales: ¿Cómo asentar un modelo solidario y duradero, en torno a la moneda única, un polo económico y social organizado y creíble? ¿Cómo construir un verdadero espacio de europeo de libertad, seguridad y justicia? ¿Cómo garantizar la eficacia de la política exterior europea a través de su componente comercial, diplomático y militar, a través de la ayuda financiera y la ayuda al desarrollo?". (COMISIÓN EUROPEA, 2002, 5)
} 
yo debate fue pospuesto hasta finales de abril como consecuencia de las tensiones entre los Estados miembros fruto de la guerra contra Irak, fueron la reforma institucional y la política exterior común.

En ese contexto y coincidiendo con la firma de los Tratados de adhesión de los diez Estados candidatos en la Cumbre extraordinaria de 16 de abril de 2003 en Atenas, el Presidente Giscard, formulo consultas a los Jefes de Estado y de gobierno sobre sus posiciones en estos ámbitos, cambiando con ello el método que hasta el momento había sido habitual de la Convención. Con las respuestas recibidas y los resultados de los debates en la Convención, el Presidium redactó su propuesta de articulado, que sometió al pleno de la Convención en la sesión plenaria de 24 y 25 de abril de 2003 para su debate, enmienda y aprobación. A partir de esta fecha se inició una fase más parecida a las tradicionales Conferencias Intergubernamentales, al centrarse las discusiones de la misma en la reforma institucional con protagonismo principal de los Estados miembros. En este sentido, puede afirmarse que hasta el acuerdo final, el protagonismo de los otros componentes de la Convención quedaría eclipsado.

La Convención, sin embargo, no ha sido prisionera de los intereses nacionales y ha mantenido aunque con insuficiencias su propósito de pensar la Unión a largo plazo e incluso unánimemente se considera que logró una mayor legitimidad al conseguir atraer la atención a los gobiernos que han dedicado un gran esfuerzo para influir en el borrador final. Lo cierto es que la inminente ampliación prevista para mayo de 2004 vino a alterar los equilibrios existentes entre los actores europeos y saco a la luz diversos debates preexistentes pero que hasta el momento se habían mantenido soterrados. Esa situación introdujo, sin embargo, una ventaja adicional ya que los desencuentros no se formularon en términos de enfrentamientos ni completos ni insalvables entre dos bandos contrapuestos, sino entre distintos círculos fluctuantes que variaban en función de la cada cuestión, lo que permitía la búsqueda de soluciones de compromiso al articularse diferentes mayorías.

En efecto, han sido precisamente las alianzas flexibles y cambiantes las que han permitido ir perfilando diversos avances a través de métodos más deliberativos que negociadores, aunque la última etapa estuvo presidida por la negociación (ALDECOA, 2003 (b), 6-7). Entre esos círculos, que trascienden a los representantes de los Gobiernos, puede enumerarse el de los federalistas, los defensores del federalismo intergubernamental ${ }^{14}$ como Francia y Alemania, los Esta-

\footnotetext{
${ }^{14}$ El concepto de federalismo intergubernamental se debe a dos politólogos franceses, Croisat y Quermonne, que lo conciben como un modelo singular que concibe elementos de integración federal con otros de cooperación entre los gobiernos para la gestión común de diferentes políti-
} 
dos fundadores, los atlantistas, los contribuyentes netos, los beneficiarios netos, los Estados pequeños, los de la ampliación, los partidarios de una defensa europea, los que defienden el modelo social europeo, etc.

No obstante, el actor clave del proceso constituyente ha sido el motor francoalemán, revitalizado desde otoño de 2002, que, ante todo, mostró su decidida voluntad de volver a liderar la profundización europea, como ocurriera en los ochenta. Francia y Alemania se han erigido en los principales defensores de potenciar la profundización del modelo europeo mezclando elementos federales e intergubernamentales. Su impulso se ha manifestado en las diversas propuestas conjuntas que han presentado a la Convención en todos los temas sustantivos: el ámbito institucional, a favor de una cooperación reforzada en materia de defensa, la contribución para un área de libertad, seguridad y justicia y la gobernanza económica. Por último, es necesario destacar que en algunas de esas iniciativas, han recibido el apoyo puntual de Italia, el Benelux, la Comisión o los grupos políticos del Parlamento Europeo.

\section{PRINCIPALES INNOVACIONES INTRODUCIDAS POR EL TEXTO DE LA CONVENCIÓN}

El día 30 de mayo, el Presidium de la Convención presentó su proyecto final, que pasó a manos de los líderes europeos el 20 de junio en Salónica. En las Conclusiones de la presidencia del Consejo de Salónica se afirma:

"El Consejo Europeo ha decidido que el texto del proyecto de tratado Constitucional es una buena base de partida para la conferencia intergubernamental. Invita a la futura presidencia italiana a lanzar, desde la sesión del Consejo de julio, el procedimiento en virtud del artículo 48 del tratado, con el objeto de que la conferencia pueda ser convocada en octubre de 2003" (CONSEJO EUROPEO DE SALÓNICa, 2003, 2)

Los últimos retoques al proyecto se produjeron durante la sesión plenaria de la Convención del 10 de julio han permitido introducir algunas mejoras en la Parte III (políticas de la Unión) especialmente respecto a: la protección de los servicios de interés general; la creación (en una declaración aneja) de un servicio diplomático europeo; la constitucionalización del método abierto de coordi-

cas. Véase al respecto: Maurice Croisat y Jean-Louis Quermonne, L'Europe et le fédéralisme, Paris, Montchrestien, 2001. 59-106. Nicolas MARISCAL, Teorías políticas de la integración europea, Madrid, Tecnos, 2003. Según Aldecoa, se trata de una creación que plasma un sincretismo entre el federalismo asimétrico alemán y el unitarismo francés: Francia acepta el modelo federal esbozado por Joschka Fischer, pero la ahorma en una "federación de Estados-nación", un concepto divulgado por Jacques Delors con algunos otros rasgos del léxico político esbozado en el proyecto de Unión Europea de Altiero Spinelli en los años ochenta (ALDECOA, 2003 (b), 8). 
nación, particularmente pertinente en el ámbito social; la preservación de la excepción cultural, solicitada encarecidamente por Francia por el restablecimiento de la unanimidad de los acuerdos sobre servicios culturales y audiovisuales; La consagración de los símbolos de la Unión Europea: el texto final incluye un artículo en la primera parte del Tratado sobre la bandera, el himno y el lema de la Unión "Unidad en la diversidad".

Respecto a los cambios en la arquitectura institucional y la definición de un modelo político de la Unión Europea ${ }^{15}$, por razones expositivas, dividiremos las innovaciones que presenta el texto de la Convención en tres bloques:

\section{Funcionamiento de la Unión: delimitación de competencias, simplifi- cación de actos jurídicos y toma de decisiones}

1) Uniformización jurídica: un texto único. El texto suprime la estructura en pilares heredada del Tratado de Maastricht y se estructura en cuatro partes:

I. Arquitectura constitucional: (preámbulo, definiciones y objetivos de la Unión, derechos fundamentales, competencias de la Unión, finanzas, acción exterior, política exterior, de seguridad y defensa común, justicia y asuntos interiores y cláusula de salida).

\section{Carta de Derechos Fundamentales ${ }^{16}$.}

III.Políticas y ejecución de las acciones de la Unión: retoman la reorganización y ocasionalmente las modificaciones de las disposiciones ya existentes en los tratados en vigor y que rigen las políticas de la Unión.

${ }^{15}$ El artículo 1del proyecto de Constitución define el modelo político europeo: "La presente Constitución, que nace de la voluntad de los ciudadanos y de los Estados de Europa de construir un futuro común, crea la Unión Europea, a la que los Estados miembros confieren competencias para alcanzar sus objetivos comunes. La Unión coordinará las políticas de los Estados miembros encaminadas a lograr dichos objetivos y ejercerá, de modo comunitario, las competencias que éstos le transfieran".

${ }^{16}$ Proclamada en Niza el 7 de diciembre de del 2000, la Carta se vincula al mantenimiento y desarrollo de un espacio de libertad, seguridad y justicia. En este sentido, la carta pretende recogiendo las tradiciones constitucionales comunes y el Convenio Europeo de Derechos del Hombre: enumerar los derechos y libertades fundamentales que deben ser respetados por las autoridades de los públicas de la Unión en sus relaciones con los ciudadanos europeos. La carta representa un jalón muy importante dentro de la construcción de la Europa política derivada de la misma noción de ciudadanía. Constituye un elemento indispensable de legitimidad política y moral, tanto para los ciudadanos como frente a la clase política, las administraciones y los poderes nacionales, así como ante los operadores sociales y económicos: La Carta espresa los valores comunes que inspiran la esencia de las sociedades semocráticas europeas y constituye, a largo plazo, la propia identidad de la Unión con la que podrían identificarse los ciudadanos. 
IV.Disposiciones generales y finales que aseguran la continuidad jurídica con los Tratados actuales, especialmente los de Amsterdam y Niza.

2) Personalidad jurídica de la Unión. El proyecto de Tratado Constitucional dota a la Unión de personalidad jurídica lo que le permitirá la firma de tratados bilaterales o multilaterales y ser miembro de organizaciones internacionales como Naciones Unidas o el Fondo Monetario Internacional.

3) Clarificación en el reparto de competencias. El texto clarifica el reparto de competencias entre la Unión y los Estados miembros. El título III de la Parte I define con detalle las competencias exclusivas de la Unión (política comercial y monetaria para la zona euro, unión aduanera, conservación de recursos biológicos marinos), los ámbitos de competencias compartidas (mercado interior, espacio de libertad y justicia, agricultura y pesca, transportes, energía, cohesión económica y social, desarrollo, protección del consumidor, "posiciones comunes de seguridad en materia de salud pública" y ámbitos de acción de apoyo (industria, salud, educación, protección civil).

4) Simplificación de los instrumentos jurídicos. El proyecto de Tratado Constitucional reduce el número de instrumentos jurídicos existentes y cambia su denominación para adoptar una terminología más próxima a las tradiciones jurídicas de los Estados miembros.

- Las Leyes europeas substituyen a los reglamentos

- Las leyes-marco europeas reemplazan a las directivas

- Los Reglamentos europeos son actos no legislativos de alcance general para la puesta en acción de actos legislativos. Estos textos de aplicación de Leyes o Leyes-marco pueden ser obligatorios en todos sus elementos o dejar a los Estados miembros la competencia de elección y de la forma.

- Las Decisiones europeas son igualmente unos textos para la puesta en marcha de actos legislativos pero que revisten un carácter de obligación en todos sus elementos para los países destinatarios conjuntamente.

- Las Recomendaciones y Comunicaciones son adoptadas por las instituciones comunitarias (Parlamento, Comisión y Tribunal de Justicia) pero sin carácter vinculante.

En general, las Leyes y Leyes-marco europeas elevan el procedimiento legislativo comunitario y son adoptadas conjuntamente por el Consejo y el Parlamento Europeo tras propuesta de la Comisión europea que dispone de derecho exclusivo de iniciativa. En el marco de las cooperaciones reforzadas, las leyes y 
las leyes marco pueden sin embargo ser adoptadas a iniciativa de un grupo de Estados miembros.

Entre las últimas enmiendas tomadas en consideración por la Convención, el 13 de junio, la innovación más notable es la introducción de un "derecho de iniciativa popular": si se reúnen un millón de firmas procedentes de diferentes países, los ciudadanos de la Unión tendrán el derecho de solicitar a la Comisión que redacte una propuesta de Ley europea.

5) Extensión del procedimiento de codecisión y de la mayoría cualificada. Prevé la utilización del procedimiento de codecisión como regla general de adopción de textos legislativos con recurso a la mayoría cualificada aunque se mantienen procedimientos diferenciados en los ámbitos de la PESC, la defensa, la cooperación judicial y la justicia penal.

El compromiso adoptado el 13 de junio prevé que a partir de noviembre de 2009 , la mayoría cualificada será obtenida cuando una mayoría simple de Estados representando al $60 \%$ de la población europea se pronuncie a favor de la adopción de una decisión o de un texto. Este es el capítulo más controvertido de la reforma.

6) Integración de la Carta de los Derechos Fundamentales. El proyecto de Tratado Constitucional dispone que "la Unión reconoce los derechos, las libertades y los principios enunciados en la Carta de Derechos Fundamentales que constituye la segunda Parte de la presente Constitución". El Reino Unido, sin embargo, ha obtenido el 13 de junio la inserción de una cláusula de interpretación que limita el alcance jurídico. En el actual Estado de cosas, la integración de la Carta no instituye, sin embargo, ninguna nueva competencia ni crea derecho positivo en esa materia.

\section{Reformas institucionales aplicables a la entrada en vigor del texto constitucional, tras la ratificación prevista por los Estados miem- bros.}

1)Un presidente permanente del Consejo. El borrador pone fin a la presidencia de turno e instituye un Presidente del Consejo estable, con los poderes estrictamente delimitados, elegido por el Consejo Europeo por mayoría simple para un mandato de dos años y medio renovable una vez. Ese Chairman no podrá conservar mandato nacional, será el encargado de preparar los trabajos del Consejo europeo, de presidir y animar los trabajos. Asímismo, asegura igualmente a su nivel la representación exterior de la Unión en las decisiones de política exterior, sin perjuicio de las competencias del Presidente de la Comisión y del Ministro de Asuntos Exteriores. 
2) Un Ministro europeo de Asuntos Exteriores. La futura Constitución crea el cargo de Ministro de Asuntos Exteriores; vicepresidente de la Comisión, será designado por el Consejo Europeo por mayoría cualificada, de acuerdo con el Presidente de la Comisión. Acumulará las funciones de Alto Representante actual del Consejo para la política exterior y de seguridad común y las de Comisario encargado de las relaciones exteriores, y conducirá la política exterior y de seguridad común.

3) Una política exterior y de defensa algo más reforzada. El texto de la Convención mantiene la regla de la unanimidad en este ámbito salvo para las decisiones tomadas bajo mandato del Consejo Europeo que serán adoptadas en votación por mayoría cualificada. Asímismo, se hace explícita la idea de que los Estados Miembros deben apoyar "activamente y sin reserva la política exterior y de seguridad común de la Unión", en directa alusión a la crisis provocada por la guerra de Irak

En materia de defensa, el texto prevé igualmente "la definición progresiva de una política de defensa común que puede conducir a una defensa común". Amplía la posibilidad de cooperaciones reforzadas en el ámbito de la defensa (prescrito por el Tratado de Niza) y decide la creación de una Agencia de Armamentos y capacidades militares, al objeto de definir una política europea de armamentos.

\section{Reformas en la arquitectura institucional europea que son aplazadas hasta el 1 de noviembre de 2009.}

1) Parlamento Europeo. El Parlamento Europeo no será reformado hasta que la Unión cuente con 28 miembros. En consecuencia su composición no sufre cambios: 736 miembros siguiendo el reparto de escaños prevista por el Tratado de Niza corregido en Copenhague. A partir del ingreso del 28 miembro se aplicará el principio de representación decrecientemente proporcional a la población de los países.

2) Comisión Europea. Hasta el 1 de noviembre de 2009, la Comisión tendrá 25 miembros -un comisario por país- los cinco países grandes renuncian a su segundo comisario como esta previsto en el Tratado de Niza. A partir del 1 de noviembre de 2009, y de forma automática, la Comisión se compondrá de 15 miembros, la rotación de Comisarios se hará sobre una base igualitaria que garantice a los países pequeños la misma representación que a los grandes. Los países que no cuenten con comisario podrán enviar un comisario delegado sin derecho de voto. Asimismo, el presidente de la Comisión será elegido por el Parlamento Europeo en mayoría simple a propuesta del Consejo (sobre la base 
de los resultados de las elecciones europeas). Probablemente, la Conferencia Intergubernamental flexibilice el número y las condiciones de los Comisarios.

3) Consejo. A partir del 2009, la mayoría cualificada será obtenida en el Consejo de Ministros si ella representa la mayoría simple de los Estados, sin embargo deben representar asimismo el 60\% de la población de la Unión. Esta disposición reemplazará el cálculo muy complicado adoptado por el Tratado de Niza en materia de ponderación de votos. Algunos países, sobre todo España y Polonia, para los que las disposiciones de Niza eran particularmente favorables, rechazan esta modificación del equilibrio de poder y pretenden reabrir el debate en la Conferencia Intergubernamental.

4) Mayoría cualificada y ponderación de voto. El compromiso alcanzado sobre las modalidades de cálculo de la mayoría cualificada y de recurso a este voto prevé un proceso en varios tiempos:

- Mantenimiento de las disposiciones de Niza sobre ponderación de votos hasta $200972,27 \%$ de los votos y $62 \%$ de la población

- Tras el 1 de noviembre de 2009 se pasa a la doble mayoría de Estados miembros (50\%) y de población (60\%) salvo que el Consejo Europeo decida otra mayoría cualificada (sobre la base de la ponderación de votos decidida en Niza) y prolongue tres años, como máximo, las disposiciones de Niza.

- En este último caso, abandono el 1 de noviembre de 2012 como muy tarde de la ponderación de votos, la doble mayoría se transformaría ahora en la norma.

Paralelamente, el texto prevé en la parte III sobre las políticas el recurso a una mayoría supercualificada, reuniendo $2 / 3$ de los estados miembros y el $80 \%$ de la población para ciertos supuestos donde se quiera salir de la unanimidad pero donde el paso de la unanimidad a la mayoría del $60 \%$, podría representar una transición demasiado brusca. Esta mayoría supercualificada existe ya en los tratados actuales para los actos del Consejo que no resultan de una propuesta de la Comisión. Esta fórmula garantizaría al mismo tiempo que un solo país no pueda bloquear la labor legislativa porque ninguno reúne por si sólo la minoría de bloqueo necesaria pero deja en evidencia el mayor peso específico de los países grandes y en especial de Alemania.

El proyecto de articulado comporta igualmente una cláusula evolutiva que permitirá al Consejo Europeo decidir, por unanimidad, transferir las materias actualmente adoptadas según la regla de la unanimidad, al campo de los procedimientos normales de la Unión (disposición ya existentes en los tratados actua- 
les para ciertos temas como es el caso del exilio y de la emigración). Este caso esta especialmente previsto para la política exterior (excepto para algunos ámbitos precisos) donde el Tratado podría prever la posibilidad de pasar de la unanimidad a la mayoría supercualificada y después a la mayoría cualificada.

Cuadro 1. Comparación sistema de votación en el Consejo Europeo

\begin{tabular}{|c|c|c|c|c|c|c|}
\hline \multicolumn{7}{|c|}{ Propuesta Constitución } \\
\hline & \multicolumn{2}{|c|}{ Población } & \multirow{2}{*}{$\begin{array}{l}\text { Votos } \\
\text { Pre-Niza }\end{array}$} & \multirow{2}{*}{$\begin{array}{c}\text { Votos } \\
\text { Niza }\end{array}$} & \multirow{2}{*}{$\begin{array}{l}\text { 1país/ } \\
1 \text { Voto }\end{array}$} & \multirow{2}{*}{$\begin{array}{l}\text { Votos/ } \\
\text { Población }\end{array}$} \\
\hline & Millones & $\%$ & & & & \\
\hline Alemania & 82,04 & 17,05 & 10 & 29 & 1 & 170 \\
\hline Francia & 58,97 & 12,25 & 10 & 29 & 1 & 123 \\
\hline Reino Unido & 59,25 & 12,31 & 10 & 29 & 1 & 122 \\
\hline Italia & 57,61 & 11,97 & 10 & 29 & 1 & 120 \\
\hline España & 39,39 & 8,18 & 8 & 27 & 1 & 82 \\
\hline Polinia & 38,67 & 8,03 & & 27 & 1 & 80 \\
\hline Rumanía & 22,49 & 4,67 & & 14 & 1 & 47 \\
\hline Holanda & 15,76 & 3,27 & 5 & 13 & 1 & 33 \\
\hline Grecia & 10,53 & 2,18 & 5 & 12 & 1 & 22 \\
\hline Rep. Checa & 10,29 & 2,13 & & 12 & 1 & 21 \\
\hline Bélgica & 10,21 & 2,12 & 5 & 12 & 1 & 21 \\
\hline Hungría & 10,09 & 2,09 & & 12 & 1 & 21 \\
\hline Portugal & 9,98 & 2,07 & 5 & 12 & 1 & 21 \\
\hline Suecia & 8,85 & 1,83 & 4 & 10 & 1 & 18 \\
\hline Bulgaria & 8,23 & 1,71 & & 10 & 1 & 17 \\
\hline Austria & 8,08 & 1,67 & 4 & 10 & 1 & 17 \\
\hline Eslovaquia & 5,39 & 1,12 & & 7 & 1 & 11 \\
\hline Dinamarca & 5,31 & 1,10 & 3 & 7 & 1 & 11 \\
\hline Finlandia & 5,16 & 1,07 & 3 & 7 & 1 & 11 \\
\hline Irlanda & 3,74 & 0,77 & 3 & 7 & 1 & 8 \\
\hline Lituania & 3,70 & 0,76 & & 7 & 1 & 8 \\
\hline Letonia & 2,44 & 0,50 & & 4 & 1 & 5 \\
\hline Eslovenia & 1,98 & 0,41 & & 4 & 1 & 4 \\
\hline Estonia & 1,45 & 0,30 & & 4 & 1 & 3 \\
\hline Chipre & 0,75 & 0,15 & & 4 & 1 & 2 \\
\hline Luxemburgo & 0,43 & 0,08 & 2 & 4 & 1 & 1 \\
\hline Malta & 0,38 & 0,07 & & 3 & 1 & 1 \\
\hline TOTAL & 481,17 & 99,86 & 87 & 345 & 27 & 1.000 \\
\hline \multirow{2}{*}{\multicolumn{3}{|c|}{ Mayoría cualificada }} & 62 votos & 255 votos & 14 estados & 600 votos \\
\hline & & & $71,30 \%$ & $73,9 \%$ & $51 \%$ & $60 \%$ \\
\hline
\end{tabular}

FUENTE: José Ignacio Torreblanca, 2003, Real Instituto Elcano. Recogido en EL PAIS, 4/10/2003.

\section{EL PROYECTO DE CONSTITUCIÓN ANTE LA CONFERENCIA INTERGUBERNAMENTAL}

La Unión Europea dispone finalmente de un anteproyecto de Constitución, algo que parecía imposible cuando arrancó la Convención. Este hecho en sí 
mismo es un gran paso adelante reconocido por la mayoría, pero el producto final en opinión de otros muchos deja bastante que desear. Las principales críticas advierten de una parte, que el Proyecto de Tratado estableciendo una Constitución para Europa debe considerarse como una construcción original escasamente homologable a un tratado constitucional; de otra, que junto a indudables avances, el ejercicio conducido por Valèry Giscard d'Estaing, lejos de un texto sencillo y ágil que se pudiera -por ejemplo- estudiar en la escuelas, ha desembocado en uno complejo y farragoso, que muy posiblemente complique el esquema institucional.

En última instancia, el texto de la Convención está en el tejado de la Conferencia Intergubernamental abierta en Roma y las perspectivas no hacen ser muy optimista en cuanto a una mejora del mismo, antes al contrario. Básicamente, la cuestión reside en saber si la Conferencia Intergubernamental va a desaprovechar los avances que se aprecian en el anteproyecto manteniendo el precario consenso adoptado - ya rechazado por España y Polonia- o va a abrir la caja de Pandora, planteando una renegociación completa del mismo hasta aspectos que pueden resultar nimios ${ }^{17}$.

Es evidente que el borrador de la Convención mejora las bases para la unión política europea y hace más explícito el contenido constitucional que ya tiene la integración europea e incluso los enfatiza con la incorporación a su articulado de la Carta de los Derechos Fundamentales de la Unión hasta el presente una simple declaración y también por la estructura del texto, en el que las partes I (principios) y II (Carta de Derechos) constituyen el núcleo duro constitucional, siendo las restantes (III y IV) las correspondientes a las políticas y a las disposiciones finales. Sin embargo, mantiene elementos ajenos a una Constitución nacional: los poderes de la Unión proceden de los países miembros; los Estados son los que adoptaran el texto y no los ciudadanos; la soberanía y su ejercicio en el exterior no es única sino complementaria, y sólo incipientemente común. Como afirma Vidal-Folch "desde un punto de vista político es casi una constitución pero formalmente es un Tratado internacional que sólo puede modificarse por unanimidad". (VIDAL-FOLCH, 2003, 26)

\footnotetext{
${ }^{17}$ Por poner un ejemplo, los sectores cristianos intentaron a lo largo de la Convención, introducir alguna referencia a Dios, o al menos a la religión, y pronto fue creciendo el tema hasta un extremo que no satisface a nadie. Hoy continúan esos esfuerzos en la CIG a través de los gobiernos italiano, español y polaco que siguen considerando como "razonable" el objetivo de que la nueva carta Magna incluya una mención a las raíces hebreas y cristianas de la cultura europea. Posiblemente, para llegar a la conclusión de que la UE se basa en una comunidad de valores no es necesario complicar tanto las cosas.
} 
Asimismo, la Convención ha logrado avances en los grandes problemas políticos que tenían una expresión técnica y en los que las anteriores Conferencias Intergubernamentales se habían quedado bloqueadas por falta de acuerdo político, aunque también se han apreciado algunas limitaciones, principalmente, en el terreno instituciona $1^{18}$, aunque no de forma exclusiva en él. Así, el Parlamento Europeo, por ejemplo, lamenta que no se haya producido una consolidación de la política económica y social y una mayor coordinación de las políticas económicas de los Estados miembros; la falta de control parlamentario sobre la Política Exterior y de Seguridad Común y la defensa; que los miembros del Tribunal de Justicia sigan nombrándose por unanimidad; el retraso de algunas reformas institucionales a noviembre de 2009; la pervivencia de la unanimidad del Consejo en algunas políticas sensibles; $\mathrm{y}$, sobre todo, que las futuras reformas constitucionales, incluso menores, tengan que seguir adoptándose por unanimidad (PE, 2003, 6-8).

A estos aspectos negativos podría añadirse algunos otros puestos de manifiesto por la Comisión Europea y la crítica especializada: que no se hayan comunitarizado suficientemente todas las políticas europeas, sobre todo, la política exterior y de seguridad común; que la fiscalidad especialmente siga sometida a la regla de la unanimidad; la falta de formalización de Mr. Euro; los pocos avances en política social y en empleo; el escaso desarrollo del modelo regional, la falta de un recurso individual ante en Tribunal de Justicia en demanda de protección de los derechos fundamentales; la carencia de un procedimiento electoral uniforme y de regulación de los partidos políticos europeos; la insuficiente parlamentarización de la elección del presidente de la Comisión; o los escasos avances en el caso del Servicio Diplomático de la Unión, sobre todo en lo relativo a la creación de Embajadas de la Unión y de un cuerpo diplomático propio y una Escuela Diplomática Europea, entre otras.

Posiblemente, una explicación de esa situación haya que buscarla en que el Proyecto de Tratado Constitucional responde por su naturaleza -una creación híbrida de naturaleza dual-, al llamado federalismo intergubernamental ${ }^{19}$.Esta

18 Por ejemplo, el presidente de la Comisión, nombrado por el Consejo Europeo a la luz de los resultados de las elecciones europeas - en realidad, un paso a medias que no limita el déficit democrático de la institución-, tendrá que competir por la visibilidad y el poder con un presidente permanente del Consejo Europeo elegido por dos años y medio entre sus pares. Este presidente, además, le pisará los talones a un ministro europeo de Asuntos Exteriores, que tendrá a la vez un pie en la Comisión.

19 "El Proyecto de Tratado Constitucional -escribe Aldecoa- consolida el modelo del federalismo intergubernamental, que se ha desarrollado en la Unión Europea, al menos en los últimos diez años, desde la vigencia del Tratado de Maastricht, el 1 de noviembre de 1993. Este modelo caracterizado por el uso conjunto de métodos federales de integración y confederales a la vez, se 
circunstancia debe destacarse nuevamente, ya que tanto por el impulso político como por la textualidad de las de las propuestas incorporadas, estamos ante un documento de inspiración esencialmente franco-alemana, sobre todo, en cuestiones clave como son la arquitectura institucional o la defensa- aunque con algunos retoques externos en otros ámbitos. O dicho de otra manera, el texto consagra el peso institucional hegemónico del país locomotora, Alemania, contra su paridad con Francia y pone en evidencia la fragilidad de la posición de España punteadas en Niza. Y de esta cuestión proceden buena parte de los problemas que esta encontrando el borrador de Tratado Constitucional en la Conferencia Intergubernamental en curso: el peligro de convertirse en una amarga batalla entre países grandes y países pequeños que aspiran a mantener su influencia en una Europa ampliada.

Indudablemente, existen aspectos en los que la Convención no ha logrado consensuar los avances deseables a juicio tanto de los grupos de trabajo como de los distintos actores europeos y entre ellos, significativamente, los Estados. De hecho, las posiciones de los países miembros ante el futuro de Europa continúan dibujando un buen número de líneas de fractura. En política exterior se observan tres posiciones: los que quieren crear un polo de poder autónomo (incluido el militar); los que se oponen a todo paso que socave el papel de la OTAN, y los neutrales de diversa índole. Respecto al modelo social, existe la división entre los que optan por un modelo neoliberal en lo económico y los que defienden la herencia del modelo social europeo erigido en la posguerra aunque son conscientes de la necesidad de introducir ciertos niveles de reforma. Sobre el modelo institucional, entre los partidarios de una Europa federal y los de una Europa de los Estados. Y sobre todo ello se superpone una división más, determinada por la relación trasatlántica, aquella que parece querer abrir una brecha entre lo que se ha dado en llamar vieja y nueva Europa $^{20}$.

\footnotetext{
manifestaba en sus orígenes de una forma implícita y se consideraba un mal menor, una fórmula transitoria, que ha ganado carta de naturaleza casi sin darnos cuenta. Con la Constitución se produce una innovación que reside en su aceptación generalizada de una forma explícita como el modelo político propio de Europa, según el cual se va a tratar de llevar a cabo el proyecto político de integración (...). El federalismo intergubernamental no es una fórmula intermedia entre posturas federalistas e intergubernamentales, que mezcle algo de las dos lógicas. Se trata, por el contrario, de una innovación, no una nueva fórmula, en la cual se afirman los dos extremos, que contiene elementos de los dos modelos y en el cual se da una cierta división "rationae materiae" (ALDECOA, 2003 (a), 48).

${ }^{20}$ A este respecto, es interesante destacar la fuerte presión diplomática de Estados Unidos para que no prosperen los tímidos planes militares europeos a los que considera una amenaza en potencia para la Alianza Atlántica.
} 
Si la Conferencia Intergubernamental enmienda de forma sustantiva el texto de la Convención, se producirá una contradicción en los términos, ya que la doble legitimidad -nacional y europea- desaparecería en el proceso constituyente, para imponerse finalmente sólo la intergubernamental. La rectificación plena del Tratado Constitucional lo convertiría en opinión de Francisco Aldecoa en una Carta en parte otorgada, despreciándose una vez más la voz de los ciudadanos europeos en la construcción de Europa, ya que no podemos olvidar que la mayoría de los convencionales eran parlamentarios, representantes de los ciudadanos en distintos niveles.

Sin duda, los desencuentros sobre votos y minorías de bloqueo en el Consejo, el número de comisarios y parlamentarios en la Eurocámara así como otros aspectos institucionales son fundamentales, pero posiblemente no conduzcan al escenario de una rectificación profunda del proyecto de tratado ya que en esta tercera fase de la reforma, la negociación directa entre gobiernos, lo que realmente cuenta es la política de alianzas y la búsqueda de proyectos en común, y los riesgos costes políticos que asumiría un país o grupo de países bloqueando la Conferencia parecen demasiado elevados. Habrá que esperar, por tanto, a la fórmulas de compromiso que presente la Presidencia Italiana

En cualquier caso, de salir adelante el texto del borrador convencional de la Conferencia Intergubernamental, como muy pronto y ya como Constitución entrará en vigor el 1 de enero de 2005, posiblemente más tarde, ya que varios países como Francia, Dinamarca o España se han comprometido a celebrar referéndum cuyos resultados en algunos casos y atendiendo a precedentes anteriores -ratificación de Maastricht-, no parecen claros ya que la tarea de persuadir a los votantes puede resultar más dura de lo que en este momento se prevé. El riesgo de que la ciudadanía rechace el resultado final es grande, en parte porque esta Convención no ha salido como la Filadelfia y su resultado parece más obra de burócratas que de políticos con visión y porque la Conferencia parece abocada a un ejercicio en que cada uno de los países miembros encuentre un acomodo que satisfaga sus intereses nacionales básicos.

Y aún así, deberá de aguardar hasta el 1 de noviembre de 2009 para que entren en vigor las principales reformas -y más controvertidas-, reformas institucionales las relativas a la Comisión y al Consejo y la ponderación del voto, es decir, el nuevo reparto de poder entre los Estados miembros. En ese sentido, no debe ignorarse lo positivo que sería que la recuperación de la iniciativa política por parte de Europa coincidiera con la recuperación económica. Por otra parte, el resultado final arroja sus zonas de sombra: a juicio de muchos es discutible que la Unión Europea sea más eficaz, democrática y transparente con esta Constitución. 
Ciertamente, el objetivo de la convivencia pacífica ya se ha logrado en Europa a través del método de solución de conflictos basado en la creación de solidaridades de hecho (ideado por los padres de Europa en la posguerra mundial), y el desarrollo de la sociedad del bienestar a partir de los años sesenta se ha transformado en un modelo que, quizás, sirva para el conjunto de la sociedad mundial. Sin embargo, en lo político, Europa continua interrogándose a sí misma. La Constitución es un primer y gran paso necesario, pero, con seguridad, no suficiente.

\section{BIBLIOGRAFIA}

AldeCOA LUZARRAGA, F. "Una Europa”: su proceso constituyente, Madrid, Biblioteca Nueva, 2003 (a).

Aldecoa LuZARRAGa, F. Primeros resultados del debate sobre el futuro de Europa: entre la profundización y la refundación: 2000-2002, 4 noviembre 2002, y El resultado definitivo de la Convención Europea: la existencia de una Constitución para Europa, 12 septiembre 2003 (b). Documentos de Trabajo, Real Instituto Elcano en: http://www.realinstitutoelcano.org..

Areilza Carvajal, J.M ${ }^{\mathrm{a}}$. «La Convención Europea. Un balance» en Politica Exterior, $\mathrm{n}^{\circ}$ 94, julio-agosto (2003) pp. 43-52.

AtTINA, F. El sistema político global. Introducción a las relaciones internacionales, Barcelona, Paidos, 2001

BENEYTO, J.M « «¿Hacia una nueva Unión Europea?» en Política Exterior, ${ }^{\circ}$ 83 septiembre-diciembre (2001), pp. 130-144

BERSTEIN, S. «Vers quelle Europe? Existe-t-il une identite européenne» en L'Europe en perspective. Cahiers français, $\mathrm{n}^{\circ} 298$ (2000), pp. 92-105.

CONSTANTINESCO, . «Quelle constituante pour quelle constitution?» en $L^{\prime} E u$ rope en formation, $\mathrm{n}^{\circ} 1,2002$, pp. 17-28.

Croisat, M Y Quermonne, J.-L. L'Europe et le fédéralisme, Paris, Montchrestien, 2001.

HABERMAS, J. «Necesita Europa una Constitución?» en The New Left Review. $\mathrm{N}^{\mathrm{o}} 9$ (2001) pp...121-134.

HABERMAS, J. «El Estado-nación europeo y las presiones de la globalización» en The New Left Review, ${ }^{\circ} 1$ (2000), pp.121-134

HELD, D. La democracia y el orden global: del Estado moderno al gobierno cosmopolita, Barcelona, Paidos, 1997.

LEINEN, J. La preparation du debat sur l'avenir de l'Union Europeenne, Rapport du Mouvement Européen, 2001.

LOUIS, J.-V. «La Convention et l'avenir de l'Union européenne» en Cahiers $d u$ droit européen, $\mathrm{n}^{\mathrm{o}} 3-4,2002$, pp. 221-247

MARISCAL, M. Teorías politicas de la integración europea, Madrid, Tecnos, 2003. 
ORTEGA, A. «Unión Europea 2000. ¿Llegará Europa a ser Europa» en Claves,

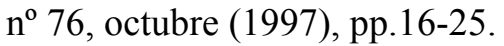

OrtegA, M. «Europa despierta» en Politica Exterior, $\mathrm{n}^{\circ}$ 94, julio-agosto (2003) pp. 55-68.

SIEDENTOP, L. La democracia en Europa, Madrid, Siglo XXI, 2001.

TOULEMON, R. «Quelle constitution pour quelle Europe» en Revue du Marché ommun et de la Union Européenne, no 448 (2001), pp. 291-306.

VIDAL-FOLCH, V. «La Constitución Europea» en Claves, $n^{\circ} 135$, septiembre (2003), pp. 24-30.

WESSELS W. Y DIETRICHS, D. «¿Qué quiere ser Europa?» en Vanguardia. Dossier ¿Qué quiere ser Europa?, nº 6, abril-junio (2003). pp. 6-17.

\section{Documentos}

CONVENCIÓN EUROPEA, Proyecto de Tratado por el que se instituye una Constitución para Europa, 18 de julio de 2003, (CONV 850/03) en http://european-convention.eu.int

CONVENCIÓN EUROPEA, Contribución de Dominique de Villepin y Joschka Fischer sobre la arquitectura institucional, Contribución $n^{\circ} 192,16$ de enero de 2003, (CONV 489/03) en http://european-convention.eu.int

Consejo Europeo De SAlÓnICA, Conclusiones de la Presidencia, 19 y 20 de junio de 2003 (SN 200/03) en http://ue.eu.int

COMISIÓN EuROPEA Comunicación de la Comisión. Un proyecto para la Unión Europea, 22 de mayo de 2001, (COM (2002) 247 Final) en http://ue.eu.int

COMISIÓN EuROPEA, Comunicación de la Comisión. Una Constitución para la Unión. 23 de diciembre de 2002, (COM (2002) 548) en http://ue.eu.int

COMISIÓN EUROPEA Libro blanco sobre la gobernanza europea "Profundizar en la democracia de la Unión Europea" 11 de octubre de 2000 (SEC (2000) 1547/7 final) en http://ue.eu.int

PARlamento Europeo. Tatsos-Mendez Vigo. Informe sobre el Tratado de Niza y el futuro de la Unión Europea. 4 de mayo de 2001 (A5-0168/2001 Final) en http://europarl.es

PARLAMENTO EUROPEO. Resolución del Parlamento Europeo sobre el Proyecto de Tratado por el que se instituye una Constitución para Europe, y que contiene el dictamen del Parlamento Europeo sobre la convocatoria de la Conferencia Intergubernamental. 24 de septiembre de 2003 (P5_TAPROV(2003)0407, Provisional) en http://europarl.es

RESUMEN: Desde principios de la pasada década se ha podido observar como periódicamente se han ido produciendo renegociaciones del Tratado de la Unión cuyos resulta- 
dos han sido mayoritariamente calificados de insuficientes. Esa valoración condujo progresivamente al convencimiento de que las reformas selectivas y parciales no garantizan el futuro de la Unión y su corolario, entre los círculos europeístas, fue la demanda de un modelo institucional claro y definido que permitiese la transformación de la Unión Europea en una estructura coherente, racional y transparente, que a su vez, permitiese el paso desde una comunidad de democracias a una democracia directa. Un convencimiento que coadyuvó la puesta en marcha de un proceso de reforma impulsado por una metodología diferente y que ha conducido a que la Unión Europea disponga actualmente de un anteproyecto de Constitución que puede alterar sustancialmente las reglas del juego y los equilibrios de poder en la ya, "una Europa".

$P A L A B R A S C L A V E$ : Unión Europea; Arquitectura Institucional Europea; Constitución Europea; Convención Europea.

ABSTRACT: From principles of last decade has been able to observe as periodically they have left renegotiations of the Treaty of the Union whose results have been qualified for the most part of insufficient taking place. That valuation led progressively to the convincing that the selective and partial reformations don't guarantee the future of the Union and its corollary one, among the circles "europeísts", the demand of a clear and defined institutional model that allows the transformation of the European Union in a coherent, rational and transparent structure was that in turn, allows the step from a community of democracies to a direct democracy. A convincing that cooperated the setting in march of a reformation process impelled by a different methodology and that it has driven to that the European Union prepares at the moment of a preliminary design of Constitution that can alter the rules of the game and the balances of power substantially already in the, an Europe.

KEY WORDS: European Union; European Institutional Construction; European Constitution; European Convention.

$\boldsymbol{R} \boldsymbol{E} \boldsymbol{S} \boldsymbol{U} \boldsymbol{M E}:$ Depuis le début de la décennie dernière, on a pu observer périodiquement des renégociations du Traité sur l'Union européenne, avec des résultats considérés dans une grande majorité comme insuffisants. Cette évaluation a conduit progressivement à la conviction que les reformes sélectives et partielles ne garantissent pas l'avenir de l'Union. La conséquence naturelle dans les milieux proeuropéens a été la demande d'un modèle institutionnel clair et bien définit permettant la transformation de l'Union européenne en une structure cohérente, rationnelle et transparente qui rendrait possible le passage d'une communauté de démocraties à une démocratie directe. Une conviction qui a contribué à la mise en route d'un processus de réforme basé sur une méthodologie différente rendant disponible un avant-projet de Constitution qui pourrait modifier substantiellement les règles du jeu et les équilibres de pouvoir existants au sein de la désormais «Europe unique».

MOTS-CLÉS: Union européenne; Architecture institutionnelle européenne; Constitution européenne; Convention européenne

RESUMO: Desde o início da passada década tem-se podido observar como é que periodicamente se têem ido produzindo renegociações do Tratado da União cujos 
resultados têem sido maioritariamente qualificados como insuficientes. Essa valoração tem conduzido de maneira progressiva à convicção de que as reformas selectivas e parciais não garantem o futuro da União e o seu corolário, entre os círculos europeístas, foi a demanda dum modelo institucional claro e definido que permitisse a transformação da União Europeia numa estrutura coerente, racional e transparente, a qual, por sua vez, permitisse a passagem desde uma comunidade de democracias para uma democracia directa. Uma convicção que tem coadyuvado para pôr em marcha um processo de reforma impulsionado por uma metodologia diferente e que tem conduzido a que a União Europeia disponha actualmente de um anteprojecto de Constituição que pode alterar substancialmente as regras do jogo e os equilíbrios de poder nesta, já, "uma Europa".

PALAVRAS CHAVE: União Europeia; Arquitectura Institucional Europeia; Constituição Europeia; Convenção Europeia. 